\title{
POR QUE O DESENVOLVIMENTO ONTOGENÉTICO FOI TRATAdo COMO UMA “CAIXA PRETA" NA SÍNTESE MOdERNA DA EVOLUÇÃo?
}

\author{
LEONARDo Augusto LuVison ARAúJo \\ Aldo MELlender de ARAúJo
}

\begin{abstract}
The Modern Evolutionary Synthesis relegated the ontogenetic development to a "black box". In this article, we argue that the absence of ontogenetic development in the Evolutionary Synthesis was due its strong foundation in transmission genetics. We discuss three research strategies of transmission genetics that created an incompatibility with the ontogenetic development: (i) particulate inheritance model; (ii) population as locus for genetics research; (iii) and experimental tools that have been applied to remove "non-heritable fluctuations" from ontogenetic and environmental effects. These practices have contributed to the strength of the genetic inheritance, but also excluded the ontogenetic development from the explanation of heredity and evolution. This distinction has been perpetuated in the Evolutionary Synthesis.
\end{abstract}

Keywords: History and Philosophy of Biology; embryology; genetics; evolutionary synthesis; scientific practices.

\section{Introdução}

A Embriologia foi um ator central dos estudos evolutivos até os primeiros anos do século XX. Importantes tentativas de abordar a evolução e a ontogenia de forma integrada estavam presentes na Embriologia Comparada e Experimental dessa época. Algumas abordagens da Embriologia Experimental, por exemplo, procuravam explicar as características morfológicas e fisiológicas da ontogenia a partir de causas físicas, químicas e fisiológicas do desenvolvimento (Amundson 2005). A elucidação dos mecanismos causais do desenvolvimento individual poderia desvendar a maneira em que a variação surge a partir da relação entre fatores hereditários e ambientais.

Contudo, tanto a Embriologia quanto a chamada herança branda ${ }^{1}$ foram excluídas da Síntese Moderna da Evolução (Geiss \& Jablonka 2011; Gilbert 1998; Hamburger 1980). Ainda que pesquisas nessa área tenham continuado, elas passaram a ser consideradas periféricas entre os evolucionistas.

As razões para essa exclusão parecem ser muitas. Mayr (1991, p.8), por exemplo, atribui a ausência da Embriologia ao próprio desinteresse dos embriologistas na Síntese Moderna. Uma evidência que apoia essa interpretação pode ser encontrada nos Principia 19(2): 263-279 (2015).

Published by NEL — Epistemology and Logic Research Group, Federal University of Santa Catarina (UFSC), Brazil. 
principais livros de Embriologia Experimental na época de desenvolvimento da Síntese Moderna, pois eles praticamente não incluíram considerações evolutivas (Hamburger 1980). Além disso, poucos embriologistas endossavam a seleção natural como o mecanismo primário da evolução. Desse modo, a interpretação de Mayr caminha no sentido de que apesar de alguns arquitetos da Síntese Moderna possuírem interesse em aspectos do desenvolvimento ontogenético - principalmente Julian Huxley (1887-1975) e Sewall Wright (1889-1998) —, a geração de embriologistas do início do século XX não quis contribuir efetivamente para a construção desta síntese.

Neste artigo pretendemos defender outro ponto de vista: a ausência do desenvolvimento ontogenético na Síntese Moderna se deveu, em grande medida, à forte fundação desta síntese teórica na genética da transmissão, a qual teve como estratégia epistemológica relegar o desenvolvimento ontogenético a uma "caixa preta". Devido a essas estratégias, considerações sobre o desenvolvimento não tiveram espaço no pensamento evolutivo. Na próxima seção, discutimos alguns antecedentes históricos dessas estratégias e, em seguida, procuramos argumentar que essa perspectiva foi central na Síntese Moderna, sendo importante para manter o poder explicativo desta síntese teórica.

\section{Estratégias de pesquisa da genética da transmissão}

O mendelismo e a Genética Clássica foram considerados praticamente sinônimos na ocasião da Third International Conference (1906) on Genetics; Hybridisation (the cross-breeding of genera or species), the cross-breeding of varieties, and general plantbreeding, em Londres (Wilks 1907). William Bateson (1861-1926) defendeu nesta conferência o uso do termo "Genética" à incipiente ciência da hereditariedade, fundando também o primeiro periódico da área — o Journal of Genetics, em 1910. Um ano antes, Wilhelm Johannsen (1857-1927) havia cunhado o termo gene para a unidade em torno da qual a nova disciplina estava se formando (Johannsen 1909).

É uma tarefa difícil, contudo, determinar as diferenças entre o mendelismo e a Genética Clássica. O mendelismo de Bateson, por exemplo, não pode ser equiparado à Genética de Johannsen, sobretudo pela forma que esses autores interpretavam os fatores responsáveis pelos caracteres. No início do século XX, Bateson ainda procurava explicar a transmissão genética e o desenvolvimento simultaneamente (Lorenzano 2006). O autor possuía um forte interesse na relação entre desenvolvimento ontogenético, hereditariedade e evolução, como pode ser constatado na sua obra Materials for the study of variation: treated with especial regard to discontinuity in the origin of species (1894).

Para Wilhelm Johannsen, por outro lado, a hereditariedade é a passagem de genes entre as gerações, sendo independente da ontogenia. Ainda que ele afirme em seu 
artigo The Genotype Conception of Heredity que "a organização como um todo nunca pode ser 'segregada' em genes" (Johannsen 1911, p.153), nesse mesmo trabalho ele define hereditariedade como "a presença de genes idênticos em ancestrais e descendentes” (Johannsen 1911, p.159), negando a importância de fatores ontogenéticos para a hereditariedade.

Essa mesma comparação pode ser feita com referência às pesquisas genéticas realizadas na Alemanha e Rússia no início do século XX, as quais nitidamente possuíam diferenças com as abordagens preponderantes na Inglaterra e Estados Unidos (Sapp 1987). Esta seção não tem como objetivo delimitar essas diferentes abordagens, mas explorar historicamente a crescente divergência entre o ponto de vista genético adotado preponderantemente na Síntese Moderna, a chamada genética da transmissão, e as abordagens que consideravam os processos ontogenéticos para a hereditariedade e evolução dos seres vivos. A questão a ser explorada é a seguinte: de que forma a genética da transmissão passa a tratar o desenvolvimento ontogenético como uma "caixa preta". E isso está expresso nas práticas que a constituíram historicamente.

\subsection{O modelo de herança de partículas}

Rudolf Ludwig Karl Virchow (1821-1902), com base no trabalho de Theodor Schwann (1810-1882), estabeleceu as bases da teoria celular há mais de 150 anos. Em sua famosa epígrafe omnis cellula e cellula, Virchow (1860) afirmava que as células são as unidades básicas da vida e, invariavelmente, originam-se de outras células. Essa ideia estava em acordo com a hipótese darwiniana de origem comum, uma vez que as células provêm de células e organismos de organismos, implicando uma continuidade física inevitável. Virchow congregava dois princípios na sua teoria celular, relacionados à composição e a gênese dos organismos: a célula é a composição básica da vida, a qual detém os caracteres dos seres; e a célula origina-se apenas de outra célula, estabelecendo uma relação de causalidade (Canguilhem 2012).

A citologia do final do século XIX, fortemente influenciada por Virchow, passa a ser um sítio de ancoragem para o discurso da hereditariedade - a célula começa a ser tratada como a portadora do material hereditário preservado, na qual a vida é originada de geração em geração. A reprodução adquiriu uma nova configuração: a formação de um ser vivo é a construção celular renovada. Com o aperfeiçoamento do microscópio vê-se que, afinal, o ovo não é senão uma célula, sendo a fecundação a fusão de duas células parentais. Esse espaço celular liga as sucessivas gerações, articulando-se com o tempo. Segundo Jacob, a célula "torna-se simultaneamente a unidade do vivente, quer dizer, a individualidade que nele detém todas as propriedades, e o ponto de partida de todo o organismo" (Jacob 1985, p.167).

Entre 1875 e 1890, a citologia teve um papel importante na tentativa de estabelecer uma conexão entre a teoria celular, o desenvolvimento e a evolução (Sapp

Principia 19(2): 263-279 (2015). 
1987). Muitos embriologistas possuíam uma visão epigenética do organismo, como resultado da relação entre as células e os fatores ambientais. O citoplasma da célula ovo parecia de alguma forma ser responsável por uma organização diretiva primordial, determinando, por exemplo, a orientação e a simetria do embrião. Isso levou a extensos estudos citológicos sobre a estrutura da célula ovo e de demonstrações experimentais da importância do citoplasma para a diferenciação embriológica (Sapp 1987).

O ponto de vista epigenético do desenvolvimento, no entanto, entrava em conflito direto com o entendimento preformacionista do organismo. A forma extrema da doutrina preformacionista encarava os organismos como miniaturas aninhadas uma dentro da outra, como uma série interminável de bonecas russas. Embora não existissem preformacionistas desse tipo no final do século XIX, é possível ver uma versão de tal visão na interpretação de que a forma adulta já está determinada por meio de partículas hereditárias (Keller 2010). Nesse contexto se estabeleceu uma disputa entre alguns embriologistas - que defendiam a importância do citoplasma e as interações epigenéticas - e os autores que possuíam um entendimento preformacionista, com a preponderância do núcleo para a hereditariedade e o desenvolvimento. Para autores como Oscar Hertwig (1849-1922), Hugo de Vries (1848-1935) e August Weismann (1834-1914) o núcleo era uma estrutura muito distinta do citoplasma, sendo primordial para o desenvolvimento e a transmissão das características de célula para célula (Sapp 1987).

Foi também no final do século XIX que os cromossomos começaram a assumir o papel principal no fornecimento da ligação entre as células ao longo das gerações. A continuidade física através do ciclo celular, a regularidade de seus números, a precisão de seus movimentos, assim como as evidências de fusão entre as células germinativas do macho e da fêmea, conferiram ao núcleo uma posição especial no discurso citológico sobre a hereditariedade (Sapp 1987). Os processos de mitose e meiose apontavam para um novo e mais profundo princípio: omnis nucleus e nucleo. Karl Wilhelm Von Nägeli (1817- 1891) foi um precursor desse princípio, ao detalhar que o núcleo de plantas e animais multiplica-se por divisão. Mas foi Walther Flemming (1843-1905) que experimentalmente detalhou algumas características nucleares, como a duplicação dos cromossomos. Dessa forma, ao pensar que o núcleo é originado de um núcleo antecessor, Flemming cunhou o aforismo omnis nucleus e nucleo, em referência ao omnis cellula e cellula de Virchow (Baker 1955).

No entanto, ainda existiam muitas dúvidas sobre a origem e a permanência dos cromossomos durante a divisão celular, bem como quanto à sua função para a hereditariedade. Os dados dos estudos citológicos ainda estavam em discussão. Apesar de a associação entre os cromossomos e os princípios mendelianos ser demonstrada por Theodor Heinrich Boveri (1862-1915) e Walter Stanborough Sutton (1877-1916) já nos anos de 1902-1903, essa ideia só foi reforçada com o estabelecimento da teo- 
ria cromossômica da herança por Thomas Hunt Morgan (1866-1945) e seus alunos (Araújo \& Martins 2008). Foi a partir de Morgan que as unidades mendelianas de herança tornaram-se as entidades materiais discretas, os "átomos" da hereditariedade. A teoria cromossômica forneceu uma compreensão da organização espacial da hereditariedade, permitindo explicá-la em termos da citologia. Os novos tipos de medição que foram introduzidos — como as inferências de distância cromossômica, reforçaram a interpretação da hereditariedade em termos de estrutura e organização material (Müller-Wille \& Rheinberger 2012). O núcleo passa a ser visto como um "centro" da atividade celular, possuindo o poder de garantir a hereditariedade e o comando da ontogenia. Esse lugar específico, "profundamente mergulhado no corpo" (Jacob 1985, p.287), permitiu separar as partículas hereditárias da experiência do organismo em seu ambiente. Bonneuil (2008) chama esse movimento de uma "santuarização" das partículas hereditárias:

\begin{abstract}
A hereditariedade passou de um universo infinito para um mundo fechado (...) Mas essa ligação foi atravessada por novas considerações sobre as unidades de herança — isoladas, tanto do ambiente quanto da experiência particular do organismo. Na virada do século [XX], as unidades orgânicas da hereditariedade não circulavam mais em todo o corpo, antes de se unir nos gametas: sua circulação estava disciplinada e estava confinada em "estirpes" (Galton 1876), no "plasma germinal" (Weismann 1883; 1892) e/ou no núcleo (Bonneuil 2008, p.87-8).
\end{abstract}

Essa "santuarização" isolou as partículas hereditárias do seu contexto: o núcleo celular passa a ser um cânone, isolado do ambiente e do restante do organismo. Essa foi uma grande reordenação de como os organismos ligam-se entre as gerações: o espaço-tempo da origem e ligação dos organismos foi "profundamente enterrado" no espaço-tempo nuclear (Bonneuil 2008, p.89). Com a primazia do núcleo, a hereditariedade torna-se uma questão de interioridade e não de interatividade. Esta concepção é muito distinta de uma visão epigenética adotada pela maioria dos embriologistas, em que o ambiente interno e externo do organismo contribuem para os processos de desenvolvimento e origem das características, envolvendo interações supracelulares, como induções e movimentos morfogenéticos (Sapp 1987).

\title{
2.2. A população como locus da prática genética
}

O trabalho experimental de Mendel combinou elementos que influenciaram os geneticistas a trabalhar com populações experimentais. Em Mendel a análise da hereditariedade não está no indivíduo, mas no conjunto de membros da descendência. Mendel deixa isso bem claro ao expor no seu clássico artigo de 1866 que seu objetivo primordial era acompanhar a "evolução" dos híbridos ao longo das gerações:

Principia 19(2): 263-279 (2015). 
A fim de descobrir as relações que as formas híbridas possuem entre si, e também com os seus progenitores, parece necessário que todos os membros da série desenvolvida em cada geração sejam, sem exceção, sujeitos a observação (Mendel 1961 [1866], p.3).

Mendel (1961 [1866]) acreditava que alguma regra para a distribuição dos caracteres só poderia ser determinada pela observação das gerações descendentes. Desse modo, o conjunto de membros da descendência foi alvo de pesquisa para Mendel através da combinação de práticas de hibridização avançada, procedimentos estatísticos combinatórios e da teoria celular de sua época. Além disso, o autor adotou uma abordagem reducionista que facilitava o trabalho experimental da hereditariedade - seu organismo modelo variava em poucos caracteres, os quais eram reduzidos a poucos "elementos" ou "fatores". Mendel também construiu analogias entre as características dos organismos e fatores contidos nas células reprodutivas. Em certo sentido, era possível "construir" o indivíduo a partir de blocos de construção elementares (Müller-Wille 2007). Essa abordagem, aliada à interpretação simbólica para os fatores da hereditariedade, permitiu articular teoria e experimentação (Jacob 1985, p.285).

A centralidade da população na prática da hereditariedade também era evidente para Francis Galton (1822-1911), primo de Darwin e um dos precursores da escola biométrica. No final do século XIX, Galton já definia a população como a unidade da hereditariedade: "a ciência da hereditariedade está interessada em fraternidades e grandes populações, ao invés de indivíduos, e deve tratá-las como unidades" (Galton 1889 , p.35). Para este autor, a população é uma entidade que obedece às suas próprias leis no que toca a hereditariedade e a variação. Isso levou a uma forte fundação da Genética em estratégias de pesquisa que tinham como foco a população, principalmente através de práticas de hibridização e do estabelecimento de linhagens puras e organismos modelo (Johannsen 1911, p.135). A combinação destas práticas experimentais permitiu não apenas construir objetos de pesquisa, mas também ferramentas para inferir a constituição genética dos indivíduos.

Isso foi essencial para abordar os problemas evolutivos, pois "a perspectiva populacional é a própria condição de possibilidade dessa ciência e constitui sua característica definidora" (Caponi 2005, p.236). Dessa forma, na figura da genética da transmissão, os primeiros arquitetos da Síntese Moderna começaram a teorizar sobre a variação populacional (cf. Fisher 1918). Essa ênfase estabeleceu uma diferença importante entre explicar as causas da variação (populacional) e as relações de causa e efeito entre os genes e o fenótipo (individual). A questão da contribuição causal para a formação de um determinado fenótipo requer conhecimento sobre o desenvolvimento ontogenético. Essa questão se refere ao nível individual e é muito distinta da herança quantitativa desenvolvida a partir da genética de populações, que se refere a diferenças entre um grupo de organismos. A Genética de População passa a 
examinar as causas da variação populacional, mas não as relações de causa e efeito na formação do fenótipo. Portanto, o que importava a respeito de um fenótipo individual na perspectiva populacional não é a sua origem (ontogenética), mas o tanto que ela desvia da média populacional (Keller 2010).

Desse modo, essa ênfase delegou o desenvolvimento ontogenético a uma "caixa preta", que não era preciso ser desvendada para as teorizações evolutivas a partir da Genética de Populações. O foco exclusivo no nível populacional foi perpetuado na Síntese Moderna, alçando a população como a principal unidade evolutiva e a seleção natural como o principal mecanismo evolutivo (Gould 1983). O indivíduo como uma unidade estrutural e fisiológica da natureza epigenética do desenvolvimento foi deixado de lado e cada característica fenotípica passou a ser explicada como um produto da seleção natural (Love 2006). O consenso formado a partir disso é de que a população seria suficiente para explicar todos os níveis da evolução dos seres vivos. Na medida em que as mudanças evolutivas se definiam como mudanças na composição genética populacional, os problemas evolutivos passaram a ser basicamente assunto da Genética de População e a Embriologia perdeu espaço no pensamento evolutivo (Folguera 2011).

\subsection{A separação entre o genótipo e as "flutuações não hereditárias" de origem ambiental e ontogenética}

A população como locus da prática genética permitiu estabelecer a herança genética em decorrência de outros parâmetros considerados "externos". Um considerável esforço foi feito pelos geneticistas nesse sentido, através de um trabalho experimental e estatístico com organismos modelos, como feijão e protozoários, procurando separar a "flutuação" causada pelo ambiente da constituição genotípica (Jennings 1910, p.140). Essas estratégias trouxeram importantes inovações para os experimentos da Genética, possibilitando controlar as variáveis de estudo e decompor os fenômenos estudados.

Johannsen (1903) contribuiu nesse sentido ao estabelecer populações de linhagens puras. Segundo Jennings (1910; 1917), o valor analítico das linhagens puras estava na possibilidade de analisar a variação, hereditariedade e evolução dos organismos. Tal prática permitia a distinção de duas coisas absolutamente diversas: as flutuações "não hereditárias", por um lado, e o genótipo permanente por outro (Jennings 1910, p.143). Mesmo que os indivíduos da linhagem diferissem entre si em uma determinada geração, tais diferenças geralmente não eram herdadas (Jennings 1910, p.137). A linhagem pura se mantinha semelhante entre as gerações na maioria dos seus aspectos porque compartilhava um mesmo genótipo: isto permitia afirmar que o genótipo constitui o autêntico aspecto da hereditariedade, negando a importância dos fatores ambientais e ontogenéticos. 
A linhagem pura como um instrumento de pesquisa colocou, inicialmente, em dúvida o poder criativo da seleção natural, pois pareciam poucas as modificações sobre as quais a seleção poderia agir e as grandes diferenças entre os indivíduos não eram significativas para a seleção atuar (Jennings 1910). No entanto, foi a partir desse instrumento de análise que a variação individual emergiu: a serialidade genealógica das linhagens puras criou uma condição experimental que propiciou a detecção de pequenas variações. As novas formas de vida criadas através de clonagem ao longo das gerações proporcionaram um controle relativo da "influência" ambiental e das "incertezas" da linhagem ancestral, possibilitando que a variação biológica seja um processo passível de comando experimental (Bonneuil 2008, p.98). A adoção de linhagens puras e de organismos modelos também conduziu a um fortalecimento da herança genética, profundamente enraizada e selada contra os efeitos do meio interno e externo (Bonneuil 2008).

Um exemplo instrutivo de como essa prática permitiu a demonstração do poder criativo da seleção natural está presente nas próprias pesquisas do biólogo Herbert Spencer Jennings (1868-1947). Segundo Stefano e Martins (2006), a partir de 1912, Jennings passa a encontrar evidências de que a seleção natural poderia agir em linhagens puras de Paramecium. Ao estudar populações de Paramecium que conjugam entre si, o biólogo americano observa a produção de uma grande variabilidade de fenótipos sobre os quais a seleção natural poderia atuar. A sua conclusão, em um artigo de 1917, é de que os estudos com diferentes organismos modelos confirmavam a eficiência da seleção natural:

Em suma, parece-me que o mendelismo e, particularmente, o trabalho com Drosophila, está fornecendo uma base completa para a evolução através de acumulação pela seleção de pequenas gradações (Jennings 1917, p.305).

Tais práticas influenciaram os primeiros arquitetos da Síntese Moderna a enfatizar a estabilidade e a eficiência causal do genótipo, as quais foram estabelecidas em decorrência da separação dos fatores ambientais e ontogenéticos. Ronald Aylmer Fisher (1890-1962) foi um caso paradigmático disso, pois ao introduzir a análise da variância ele permitiu a decomposição da variabilidade fenotípica em uma população nos seus componentes genotípicos e ambientais (Fisher 1918). O seu principal problema foi responder o quanto da variação em uma determinada população foi devido a diferenças na hereditariedade e no ambiente. Para Fisher (1918, p.400), a variação das características biológicas é determinada principalmente pelos fatores mendelianos. Dedicado ao desenvolvimento de métodos quantitativos para avaliar a importância relativa da hereditariedade e do ambiente para a variação populacional, o autor acreditava que a interação genótipo-ambiente era uma complicação potencial em suas técnicas estatísticas. Essa interação complicava os esforços estatísticos de Fisher em dividir as fontes de variação em uma população (Tabery 2008). O autor 
procurou consolidar, através de modelos evolutivos da genética de populações, a "influência da hereditariedade" (genotípica) e as "influências externas", duas categorias de causas cuja relação foi concebida como aditiva em vez de interativa.

A análise da importância relativa dos fatores ambientais e genotípicos só foi possível em condições nas quais esses fatores causais eram considerados independentes. O cálculo da variação genética em relação à variação global do fenótipo seria sem sentido na presença de qualquer interação estatística ou constitutiva entre o ambiente e o genótipo. A partição das causas da variação fazia sentido, portanto, apenas no nível populacional, pois a formação do fenótipo do indivíduo envolve interações ambientais e ontogenéticas durante o desenvolvimento (Keller 2010).

Johannsen (1911) foi um autor central nessa separação, pois ele originalmente apresentou a importante distinção entre genótipo e fenótipo, decompondo os seres vivos em sua composição genética (hereditária) e epigenética (hereditária + ambiental). A distinção entre genótipo e fenótipo oferecia a possibilidade de isolar os efeitos da herança genética — nas populações de linhagens puras — dos fatores ambientais e ontogenéticos. Apesar de essa separação ter sentido apenas em um nível populacional e de essa distinção implicar, implicitamente, o reconhecimento do desenvolvimento e o papel do ambiente na formação das características fenotípicas, na prática, muitos geneticistas ignoraram os fatores não-genéticos. Alguns mendelistas ainda tentaram manter uma ligação estreita entre hereditariedade e desenvolvimento, especialmente William Bateson e Hugo de Vries (1848-1935), mas o sucesso da Genética fez com que se começasse a enfatizar cada vez mais os problemas relacionados com a transmissão de genes (Gilbert 1998). Essa ênfase ficou mais forte após a publicação dos mecanismos da herança mendeliana por Thomas Morgan (1915) e seus colaboradores. Morgan passa a defender explicitamente a separação entre a herança genética e o desenvolvimento, apesar de ter a Embriologia como fator crítico em sua formação inicial:

Uma mudança em um gene produz efeitos definitivos nos processos de desenvolvimento. Ela afeta um ou mais dos caracteres que aparecem em algum momento no indivíduo. Neste sentido, a teoria do gene é justificada sem a tentativa de explicar a natureza dos processos causais que ligam o gene e os caracteres (Morgan 1926, p.26-7).

A teoria do gene, como formulada por Morgan, nada diz em relação ao modo pelo qual os genes estão ligados causalmente com o produto final, os caracteres. Dessa forma, o estudo da hereditariedade ficou definido por Morgan como a disciplina das causas da transmissão genética, excluindo o citoplasma e o desenvolvimento do reino da hereditariedade. Morgan fez ainda mais do que separar a Embriologia e a Genética: ele redefiniu a primeira em termos genéticos, tornando o desenvolvimento um mero epifenômeno dos genes. Nessa definição, os genes controlam o desenvolvimento e, para conhecer esse processo, os embriologistas devem estudar a expressão 
dos genes. É dessa forma que se inaugura uma nova e muito diferente agenda para a Embriologia, uma vez que os embriologistas geralmente não tinham interesse na expressão dos genes (Gilbert 1998).

Para a maioria dos embriologistas, o fenótipo de um indivíduo é uma interação inseparável entre hereditariedade e ambiente: o gene não poderia "causar" diretamente o fenótipo de um indivíduo, o qual não pode ser dividido em fatores genéticos e ambientais. A genética da transmissão como uma ciência populacional podia falar sobre genes que desencadeiam diferentes efeitos no fenótipo, mas não sobre a explicação causal desses efeitos. Isso se referia ao desenvolvimento ontogenético, que foi tratado como uma "caixa preta".

\section{As consequências para a Síntese Moderna}

As distinções discutidas anteriormente foram perpetuadas na Síntese Moderna, levando o importante arquiteto Ernst Mayr a narrar em que medida o estudo da hereditariedade não poderia desenvolver teorias bem-sucedidas até que esse fenômeno fosse concebido de forma separada do desenvolvimento ontogenético:

Todos os geneticistas de Nägeli e Weismann até Bateson não conseguiram
desenvolver teorias bem-sucedidas da hereditariedade porque tentaram ex-
plicar simultaneamente herança (transmissão do material genético de ge-
ração em geração) e desenvolvimento (...) Foi o gênio de Morgan que pôs
de lado todas as questões fisiológicas do desenvolvimento (apesar de ele
próprio ter vindo da Embriologia) e se concentrou estritamente nos proble-
mas de transmissão [genética]. Suas descobertas pioneiras de 1910-1915
foram inteiramente devidas a essa sábia restrição. Os problemas do desen-
volvimento que suas descobertas (e as de seus colaboradores) promoveram
foram simplesmente abandonadas (Mayr 1982, p.832).

Se Morgan separa a hereditariedade e o desenvolvimento e redefine a Embriologia como o estudo da expressão gênica, seu aluno Theodosius Dobzhansky (19001975) trata de definir a evolução como mudanças na composição genética das populações ao longo do tempo (Dobzhansky 1937, p.11-2). As discussões evolutivas rotineiramente pulam do fenótipo ao genótipo, deixando de lado o desenvolvimento. Na Síntese Moderna, isso não foi apenas uma questão de ênfase ou um mero recurso metodológico da pesquisa genética: ela reflete uma convicção de que os efeitos ambientais e ontogenéticos são "ruídos" do processo evolutivo, o qual é essencialmente genético (West-Eberhard 2003). Dessa forma, a Evolução e a Embriologia, que tinham sido tradicionalmente ciências do fenótipo, passam a receber definições genéticas.

Essa abordagem levou a duas consequências: a estabilidade da herança genética permite que a Síntese Moderna não tenha uma teoria da construção do fenótipo e, 
portanto, abdique do desenvolvimento; e a Síntese Moderna não estabeleceu uma clareza causal das relações entre os genes, o desenvolvimento e a evolução fenotípica (West-Eberhard 2003). Compreender o fenótipo em um sentido evolutivo requer a compreensão dos processos ontogenéticos pelo qual ele é produzido e as maneiras pelas quais esses processos podem ser alterados durante a evolução. Contudo, se um único alelo pode ser considerado como a causa de uma característica fenotípica, então é possível explicar características do organismo adulto sem qualquer referência aos processos ontogenéticos envolvidos. Na Síntese Moderna, todas as novidades evolutivas começam no interior das células, devido a alterações no núcleo, e tem um fluxo único em direção ao fenótipo. A teoria da organização biológica da Síntese Moderna considera que a mutação é a fonte última e única de características fenotípicas e das novidades evolutivas, por isso, ela está aquém de mostrar como genótipo, fenótipo e desenvolvimento estão relacionados na evolução (West-Eberhard 2003).

Além de relegar a ontogenia a uma "caixa preta", o ponto de vista genético adotado na Síntese Moderna implicou em uma diminuição do papel do ambiente no processo evolutivo. Na Síntese Moderna o ambiente tem importância evolutiva na adaptação dos organismos. No entanto, o papel da interação ambiente-desenvolvimento na origem das novidades evolutivas foi colocado de lado em meados do século XX, quando as abordagens da Genética de População para as questões evolutivas ganharam ascendência (Love 2006). A explicação da origem das novidades evolutivas foi subordinada em termos de seleção operando em populações mendelianas sujeitas a migração, mutação e recombinação (Love 2006).

Os autores que consideravam a relevância das interações ambiente-desenvolvimento na origem das novidades evolutivas tiveram uma influência limitada. É possível encontrar alguma influência de autores como Conrad Hal Waddington (19051975) e Ivan Schmalhausen (1884-1963) na literatura principal da Síntese, mas elas são escassas (Amundson 2005). As abordagens desenvolvimentais sobre a interação hereditariedade-ambiente eram muito distintas das propostas oriundas da genética da transmissão. Conceitos como "plasticidade fenotípica", "seleção estabilizadora", "norma de reação" e "assimilação genética" eram usados por alguns embriologistas para discutir a contribuição do ambiente na origem de novidades fenotípicas. Os conceitos de assimilação genética (para Waddington [1942]) e seleção estabilizadora (para Schmalhausen [1949]), por exemplo, abordavam a plasticidade nos processos ontogenéticos que a seleção natural pode atuar de forma a substituir o fenótipo condicionado pelo ambiente por um fenótipo condicionado pelo genótipo.

Contudo, a ação da seleção natural a partir da plasticidade do desenvolvimento foi reinterpretada na Síntese Moderna como um pano de fundo para a adaptação (Amundson 2005). O termo seleção estabilizadora passa a ter um significado populacional na Síntese Moderna, ao se referir à seleção dos indivíduos médios em uma população. Essa definição remove toda a referência aos fenótipos alternativos ambi- 
entalmente induzidos no desenvolvimento ontogenético, como proposto por Schmalhausen (1949).

Sahotra Sarkar (1999) explora de que forma Dobzhansky reinterpretou o conceito de norma de reação para um significado adaptativo. Após se mudar da União Soviética para os EUA em 1927, Dobzhansky introduziu a visão consensual dos cientistas da União Soviética sobre a norma de reação. Pouco tempo depois, no entanto, ele passa a desenvolver esse tema com referência a populações em vez de indivíduos, removendo a referência com a ontogenia:

Populações naturais de Drosophila, do homem e, presumivelmente, de todos os organismos diplóides e exocruzados contém inúmeros genótipos. A maioria destes genótipos tornam seus portadores razoavelmente bem adaptados para sobreviver e se reproduzir em ambientes onde a população se encontra frequentemente. A matriz de tais genótipos constitui a norma adaptativa da espécie ou da população (Dobzhansky \& Spassky 1963, p.1467, grifo nosso).

Dessa forma, Dobzhansky redefiniu a norma de reação como uma "norma adaptativa", relacionada com a genética de populações naturais e sem referência ao desenvolvimento ontogenético (Sarkar 1999).

Essas mudanças conceituais denotam o esforço de alguns arquitetos da Síntese Moderna em remover a referência à ontogenia, substituindo-a por uma definição da Genética de Populações. Estes são exemplos específicos de como a Embriologia foi tratada como uma "caixa preta" no quadro teórico da Síntese Moderna. Esse tratamento foi importante para o movimento unificador desta síntese em torno da Genética de População, pois estava em jogo se os inúmeros estudos microevolutivos teriam um poder explicativo menor no estudo da evolução da vida como um todo. G.G. Simpson (1944) problematiza essa questão ao discutir o tema da macroevolução, um ponto de disputa entre as abordagens microevolutivas e desenvolvimentais:

Macroevolução envolve o surgimento e a divergência de grupos descontínuos; ainda é discutível se ela difere da microevolução em tipo ou apenas em grau. Se ambas provarem ser basicamente diferentes, os inúmeros estudos de microevolução tornar-se-iam relativamente sem importância e deveriam ter um valor menor no estudo da evolução como um todo (Simpson 1944, p.97).

Em contraponto ao continuum micro e macroevolução, alguns embriologistas adotavam uma perspectiva dramaticamente distinta sobre o ritmo e os processos da evolução fenotípica. Um exemplo importante é de Richard Goldschmidt (18781958), uma das principais autoridades da comunidade científica mundial em questões de determinação do sexo (Richmond 1986). Uma das razões pelas quais ficou célebre reside também sobre as suas ideias evolutivas e as tensões que elas suscitaram na Síntese Moderna. Na obra The Material Basis of Evolution (1960[1940]), o autor

Principia 19(2): 263-279 (2015). 
entra em conflito com os consensos da síntese de tantas maneiras que esse livro serviu como um ponto de encontro para as críticas dos arquitetos da Síntese Moderna (Gould 2002). A principal tese desse livro é de que a microevolução e a macroevolução são fenômenos distintos e que o acúmulo lento e gradual de micromutações não é suficiente para explicar as lacunas de algumas linhagens evolutivas.

Goldschmidt (1960) argumenta que a evolução das espécies envolve, sobretudo, mutações sistêmicas em grande escala e macromutações no desenvolvimento dos organismos. ${ }^{2} \mathrm{O}$ ponto de vista de que as mudanças evolutivas envolvem as vias de desenvolvimento foi discutido por Goldschmidt a partir de diferentes conceitos, como norma de reação, fenocópia e processos morfogenéticos.

O conceito de norma de reação foi importante para o autor na discussão das potencialidades do desenvolvimento, pois em condições ambientais modificadas a norma de reação é polimorfa. Quer dizer, o mesmo genótipo pode ser capaz de produzir, em condições alternativas, fenótipos com um grande grau de diferença. Com isso, Goldschmidt (1960) esperava mostrar que modificações no desenvolvimento poderiam gerar mudanças da ordem de magnitude macroevolutiva:

Em um genótipo constante, as potencialidades do desenvolvimento individual podem incluir um alcance de variação da mesma ordem fenotípica de magnitude que, em outros aspectos, caracteriza as grandes etapas evolutivas baseadas em mudanças do genótipo (Goldschmidt 1960, p.260).

A Base Material, dessa forma, concede ao tema do desenvolvimento uma proeminência clara no espaço e tempo da evolução. Goldschmidt usou o termo "base material da evolução" para enfatizar seu ponto de vista materialista, ao rejeitar o vitalismo, enquanto, ao mesmo tempo, se afastava da noção atomística do gene (Dietrich 2003), delegando um papel especial para as potencialidades do desenvolvimento que a natureza pode "utilizar" no processo evolutivo (Goldschmidt 1960, p.4).

A sua atitude crítica frente ao conceito clássico de gene é relatada em uma correspondência com Leslie Clarence Dunn (1893-1974), uma das figuras mais significativas da genética do desenvolvimento da primeira metade do século XX: "agora declarado por escrito, como antes apenas oralmente, não existe tal coisa como gene" (Goldschmidt 1937 apud Dietrich 2000, p.95). Algumas críticas presentes na base material da evolução seriam consequências filogenéticas do posicionamento de Goldschmidt sobre o gene clássico, na procura de um novo quadro teórico mais ampliado e de acordo com as diferentes disciplinas biológicas. O autor procurava um esquema geral da evolução em harmonia com a Taxonomia, Morfologia, Embriologia e Paleontologia, assim como dos novos desenvolvimentos da Genética (Goldschmidt 1960, p.397).

Para Goldschmidt (1960), a genética de Morgan centrada no gene clássico e na transmissão genética deveria ser substituída pela "Genética Fisiológica", a qual inte- 
grava a hereditariedade com processos do desenvolvimento e da fisiologia. Morgan usou o envelope nuclear como uma barreira conceitual e disciplinar. A Genética seria o estudo da transmissão de características através do núcleo e os embriologistas deveriam estudar a expressão dessas características no citoplasma. Esta divisão permitiu que cada disciplina prosseguisse separadamente. Goldschmidt desafiava essa separação e, além disso, criticava os principais aspectos da Síntese Moderna que foram sedimentados a partir desse ponto de vista genético.

Isso fez com que Goldschmidt fosse considerado um herege por muitos de seus pares (Dietrich 2003). Ele é lembrado pelos historiadores e por aqueles que conviveram no seu ambiente acadêmico (cf. Gould [2002]) como alguém "pouco ortodoxo", "dissidente" e "controverso" (Richmond 2007, p.172). Tais críticas são naturalmente esperadas por alguém que procurava diminuir o poder explicativo do gene clássico e lançava sérias objeções às abordagens dos arquitetos da Síntese Moderna, colocando uma grande ênfase no desenvolvimento, o qual seria um processo ativo e não uma condição passiva de fundo, mediadora entre o genótipo e fenótipo. Ao concentrar muito de sua atenção no desenvolvimento, Goldschmidt também diminuía a importância do enfoque populacional no processo evolutivo (Dietrich 2003), desafiando as principais estratégias que levaram à incompatibilidade entre a genética da transmissão e o desenvolvimento ontogenético.

\section{Considerações finais}

As estratégias de pesquisa da genética da transmissão, como a ênfase nas regularidades das populações; o modelo de herança de partículas, separadas tanto de influências do ambiente externo quanto do ambiente interno; e a adoção de ferramentas experimentais que procuraram remover "flutuações não hereditárias" de origem ambiental e ontogenética, abriram novos e fecundos caminhos para estudar a herança genética, mas também excluíram o desenvolvimento ontogenético da explicação causal da hereditariedade e evolução dos seres vivos. A partir destas estratégias, se adquiriu uma forma de síntese teórica e explicativa na evolução, possibilitando uma maior generalidade e extensão da Síntese Moderna. Uma das formas de manter constantemente a coerência desta síntese teórica, e o seu alcance explicativo, ocorreu pela disputa sobre os processos evolutivos. Abordagens desenvolvimentais não compartilhavam diversos aspectos da genética da transmissão e entraram em conflito com muitos de seus pressupostos, pois estavam voltadas para as regularidades individuais, com um papel importante da interação entre o ambiente interno e externo. Mesmo autores que tentaram um diálogo entre a Genética e a Embriologia, como Richard Goldschmidt, permaneceram isolados ou em conflito com os teóricos da Síntese Moderna.

Principia 19(2): 263-279 (2015). 
Devido à forte fundação da Síntese Moderna na genética da transmissão o desenvolvimento ontogenético foi tratado como uma "caixa preta" e a Embriologia foi excluída desta síntese. Isso levou a uma negligência das considerações sobre a interação hereditariedade-ambiente e dos estudos com outros níveis hierárquicos na evolução biológica — além do populacional —, os quais não tiveram espaço no pensamento evolutivo ao menos até a metade do século XX.

\section{Referências}

Amundson, R. 2005. The Changing Role of the Embryo in Evolutionary Thought: Roots of EvoDevo. Cambridge: Cambridge University Press.

Araújo, A. M; Martins, L.A-C.P. 2008. A teoria cromossômica da herança e a teoria do plastinema de Toledo Piza Jr.: um confronto esquecido. Filosofia e História da Biologia 3: 1-19.

Bateson W. 1894. Materials for the study of variation: treated with especial regard to discontinuity in the origin of species. London: Macmillan.

Baker, J. R. 1955. The Cell-theory: a Restatement, History, and Critique. Quarterly Journal of Microscopical Science 96: 449-81.

Bonneuil, C. 2008. Producing Identity, Industrializing Purity: Elements for a Cultural History of Genetics. In: S. Müller-Wille; H-J. Rheinberger (eds.) A Cultural History of Heredity, IV. Berlin: MPIWG Preprint.

Canguilhem, G. 2012. O conhecimento da vida. Rio de Janeiro: Forense.

Caponi, G. 2005. O darwinismo e seu outro, a teoria transformacional da evolução. Scientiæ Studia 3(2): 233-42.

Dietrich, R. M. 2000. From Gene to Genetic Hierarchy: Richard Goldschmidt and the Problem of the Gene. In: P. Beurton; R. Falk; H-J. Rheinberger (eds.) The Concept of the Gene in Development and Evolution: Historical and Epistemological Perspectives, p.91-114. Cambridge: Cambridge University Press.

- 2003. Richard Goldschmidt: hopeful monsters and other 'heresies'. Nature Reviews Genetics 4: 68-74.

Dobzhansky, T. H. 1937. Genetics and the Origin of Species. New York: Columbia University Press.

Dobzhansky, T. H; Spassky, B. 1963. Genetics of Natural Populations. Xxxiv. Adaptive Norm, Genetic Load and Genetic Elite in Drosophila Pseudoobscura. Genetics 48: 1467-85.

Fisher, R. A. 1918. The Correlation between Relatives on the Supposition of Mendelian Inheritance. Philosophical Transactions of the Royal Society of Edinburgh 52: 399-433.

Folguera, G. 2011. Filosofía de la Biología: Análisis crítico de las jerarquías en la teoría de la evolución. Editorial Académica Española.

Galton, F. 1889. Natural inheritance. New York: Macmillan and Co.

Geiss, S. B; Jablonka, E. 2011. Transformations of Lamarckism: From Subtle Fluids to Molecular Biology. Cambridge: MIT Press.

Gilbert, S. 1998. Bearing Crosses: A Historiography of Genetics and Embryology. American Journal of Medical Genetics 76: 168-82.

Goldschmidt, R. 1960. The material basis of evolution. New Jersey: Pageant Books.

Principia 19(2): 263-279 (2015). 
1937. To L. C. Dunn; November 3: L. C. Dunn Papers. American Philosophical Society Library: Philadelphia.

Gould, S. J. 1983. The hardening of the modern synthesis. In: M. Grene (ed.) Dimensions of Darwinism, p.71-93. Cambridge: Cambridge University Press.

- 2002. Structure of evolutionary theory. Harvard: Belknap Press.

Hamburger, V. 1980. Embryology and the modern synthesis in evolutionary theory. In: E. Mayr; W. Provine (eds.) The evolutionary synthesis: perspectives on the Unification of Biology, p.97-112. New York: Cambridge University Press.

Jacob, F. 1985. A lógica da vida. Lisboa: Dom Quixote.

Jennings, H. S. 1910. Experimental evidence of the effectiveness of selection. The American Naturalist 44: 136-145.

-1917. Modifying factors and multiple allelomorphs in relation to the results of selection. The American Naturalist 51: 301-307.

Johannsen, W. L. 1903. Heredity in population and pure lines. In: J. A. Peters (ed.) Classic Papers in Genetics (1961), p.20-6.

- 1909. Elemente der exakten Erblichkeitslehre. Zeitschrift für Induktive Abstammungs und Vererbungslehre 2: 136-7.

- 1911. The genotype conception of heredity. The American Naturalist 45: 129-59.

Keller, F. E. 2010. The Mirage of a Space between Nature and Nurture. Durham: Duke University Press.

Lorenzano, P. 2006. La emergencia de un programa de investigación en genética. In: L. AC. P. Martins; A-C. K. Regner; P. Lorenzano (eds.) Ciências da vida: estudos filosóficos e históricos. Campinas: Associação de Filosofia e História da Ciência do Cone Sul.

Love, A. C. 2006. Explaining evolutionary innovation and novelty: a historical and philosophical study of biological concepts. Tese de Doutorado. University of Pittsburgh.

Mayr, E. 1982. The growth of biological thought: Diversity, evolution, and inheritance. Cambridge, Mass., and London: Belknap Press of Harvard University Press.

— 1991. An overview of current evolutionary biology. In: L. Warren; H. Koprowski (eds.) New perspectives on evolution, p.1-14. New York: Wiley Liss.

Mendel, G. J. 1866. Versuche über Pflanzen-Hybriden [Experiments in Plant Hybridization]. In: J. A. Peters (ed.) Classic Papers in Genetics, p.1-20, (1961).

Morgan, T. H. 1926. The Theory of the Gene. New Haven, CT: Yale University Press.

Morgan, T. H; Sturtevant, A. H; Muller, H. J; Bridges, C. B. 1915. The Mechanism of Mendelian Heredity. New York: Henry Holt and Company.

Müller-Wille, S. 2007. Hybrids, pure cultures, and pure lines: from nineteenth-century biology to twentieth-century genetics. Studies in History and Philosophy of Science Part C: Studies in History and Philosophy of Biological and Biomedical Sciences 38: 796-806.

Müller-Wille, S; Rheinberger, H-J. 2012. Cultural History of Heredity. Chicago: University of Chicago Press.

Richmond, M. 1986. Richard Goldschmidt and Sex Determination: The Growth of German Genetics, 1900-1935. Tese de Doutorado. Indiana University (USA).

- 2007. The Cell as the Basis for Heredity, Development, and Evolution: Richard Goldschmidt's Program of Physiological Genetics. In: D. Manfred; Laubichler; J. Maienschein (eds.) From embryology to Evo-Devo A History of Developmental Evolution. Cambridge: MIT press.

Principia 19(2): 263-279 (2015). 
Sarkar, S. 1999. From the Reaktionsnorm to the Adaptive Norm: The Norm of Reaction, 19091960. Biology and Philosophy 14: 235-252.

Sapp, J. 1987. Beyond the Gene: Cytoplasmic Inheritance and the Struggle for Authority in Genetics. Oxford: Oxford University Press.

Simpson, G. G. 1944. Tempo and Mode in Evolution. Columbia University Press.

Stefano, W; Martins, L.A-C.P. 2006. Herbert Spencer Jennings e os efeitos da seleção em Paramecium: 1908-1912. Filosofia e História da Biologia 1: 351-69.

Schmalhausen, I. I. 1949. Factors of evolution. Philadelphia: Blakiston.

Tabery, J. R. A. 2008. Fisher, Lancelot Hogben, and the Origin(s) of Genotype-Environment Interaction. Journal of the History of Biology 41: 717-61.

Waddington, C. H. 1942. Canalization of development and the inheritance of acquired characters. Nature 150: 563-5.

West-Eberhard, M. J. 2003. Developmental Plasticity and Evolution. New York: Oxford University Press.

Wilks, W. 1907. Report of the Third International Conference 1906 on Genetics: Hybridisation (the Cross-breeding of Genera Or Species), the Cross-breeding of Varieties, and General Plantbreeding. London: Royal Horticultural Society.

Virchow, R. L. K. 1860. Cellular pathology as based upon physiological and pathological histology. Philadelphia: J. B. Lippincott.

LEONARDo Augusto Luvison ARAúJo Universidade Federal do Rio Grande do Sul

Colégio de Aplicação

leonardo_luvison@hotmail.com

Aldo Mellender de ARAúJo

Universidade Federal do Rio Grande do Sul

Departamento de Genética

\section{Notas}

${ }^{1}$ Esse termo foi usado por Ernst Mayr (1982) para descrever o tipo de herança em que as variações são maleáveis e podem ser produzidas pelo efeito do ambiente, ou pelo uso e desuso, e são transmitidas à descendência de uma forma menos robusta e previsível do que os fatores mendelianos "duros".

${ }^{2}$ Mutações sistêmicas seriam grandes rearranjos nos cromossomos, os quais poderiam levar a um sistema de reação capaz de gerar um novo fenótipo repentinamente. Esse mecanismo era central na concepção de Goldschmidt de macroevolução. Da mesma forma, mutações importantes do desenvolvimento poderiam produzir grandes efeitos fenotípicos. Essas macromutações do desenvolvimento produziriam "monstros esperançosos", os quais seriam a personificação das alterações fenotípicas que tinham o potencial de formar novas espécies (Dietrich 2003).

Principia 19(2): 263-279 (2015). 